\title{
Functional characterization of Candida albicans Hos2 histone
}

\section{deacetylase [version 1; peer review: 2 approved with}

\section{reservations]}

\section{G Karthikeyan ${ }^{1}$, Maneesh Paul-Satyaseela1,2, Nachiappan Dhatchana Moorthy ${ }^{1}$, Radha Gopalaswamy1', Shridhar Narayanan ${ }^{1,3}$}

\author{
${ }^{1}$ Drug Discovery Research, Orchid Chemicals and Pharmaceuticals Limited, Chennai, 600 119, India \\ ${ }^{2}$ Current address: Samrud Foundation for Health \& Research, Bangalore, 560106, India \\ ${ }^{3}$ Current address: AstraZeneca India Pvt. Ltd, Bengaluru, 560024, India
}

V1 First published: 11 Nov 2013, 2:238

https://doi.org/10.12688/f1000research.2-238.v1

Second version: 23 May 2014, 2:238

https://doi.org/10.12688/f1000research.2-238.v2

Latest published: 22 Jul 2014, 2:238

https://doi.org/10.12688/f1000research.2-238.v3

\begin{abstract}
Candida albicans is a mucosal commensal organism in normal individuals, but is a major pathogen causing systemic and mucosal infections in immunocompromised individuals. Azoles have been very effective anti-fungal agents and the mainstay in treating opportunistic mold and yeast infections. Azole resistant strains have emerged compromising the utility of this class of drugs. It has been shown that azole resistance can be reversed by the co-administration of a histone deacetylase (HDAC) inhibitor, suggesting that resistance is mediated by epigenetic mechanisms possibly involving Hos2, a fungal deacetylase. We report here the cloning and functional characterization of HOS2 (High Osmolarity Sensitive), a gene coding for fungal histone deacetylase from $C$. albicans. Inhibition studies showed that Hos2 is susceptible to pan inhibitors such as trichostatin A (TSA) and suberoylanilide hydroxamic acid (SAHA), but is not inhibited by class I inhibitors such MS-275. Purified Hos2 protein consistently deacetylated tubulins, rather than histones from TSA-treated cells. This in vitro enzymatic assay, which is amenable to high throughput could be used for screening potent fungal Hos2 inhibitors that could be a potential anti-fungal adjuvant. Hos2 has been reported to be a putative NAD+ dependent histone deacetylase, a feature of sirtuins. We assayed for sirtuin activation with resveratrol and purified Hos2 protein and did not find any sirtuin activity.
\end{abstract}

Keywords

C. albicans, HOS2, enzyme assay, histone/ tubulin deacetylase activity.




Corresponding author: G Karthikeyan (karthik@orchidpharma.com)

Competing interests: No competing interests were disclosed.

Grant information: This was an exploratory in-house project funded solely by Orchid Chemicals and Pharmaceuticals Limited.

The funders had no role in study design, data collection and analysis, decision to publish, or preparation of the manuscript.

Copyright: ( 2013 Karthikeyan G et al. This is an open access article distributed under the terms of the Creative Commons Attribution License, which permits unrestricted use, distribution, and reproduction in any medium, provided the original work is properly cited. Data associated with the article are available under the terms of the Creative Commons Zero "No rights reserved" data waiver (CC0 1.0 Public domain dedication).

How to cite this article: Karthikeyan G, Paul-Satyaseela M, Dhatchana Moorthy $\mathrm{N}$ et al. Functional characterization of Candida albicans Hos2 histone deacetylase [version 1; peer review: 2 approved with reservations] F1000Research 2013, 2:238 https://doi.org/10.12688/f1000research.2-238.v1

First published: 11 Nov 2013, 2:238 https://doi.org/10.12688/f1000research.2-238.v1 


\section{Introduction}

Candida albicans is a commensal organism found in the mucosa and gastrointestinal tract of most healthy individuals but can cause severe systemic/superficial infections, especially in immunocompromised patients ${ }^{1}$. This fungus is of clinical importance and is one of the leading causes of systemic infections in immunocompromised individuals. C. albicans is the fourth most common cause of nosocomial bloodstream infections and is associated with high mortality rates ${ }^{2}$. Azoles and echinocandins targeting the ergosterol and cell wall biosynthesis pathway respectively have been used as anti-fungal drugs though the emergence of drug-resistant strains has compromised the efficacy and utility of these drugs ${ }^{3}$.

Azole resistance in Candida sp. is mediated by up regulation of genes encoding ERG11, a lanosterol demethylase ${ }^{4-6}$, MDR $^{5,7}$ and by CDR (Candida drug resistance) efflux pumps ${ }^{5,7-9}$. A combination of existing anti-fungals with new classes of drugs that act by different mechanisms will be viable alternatives to the current monotherapy regimen, which contributes to the emergence of drug resistance.

Histone deacetylases (HDAC) play an important role in modulating chromatin conformation, by deacetylating crucial lysine residues in the histone octamers over which the chromatin DNA are wrapped ${ }^{10}$. Human HDAC's fall into four broad categories, Class I (HDAC1, 2, 3, and 8), Class II a (HDAC 4, 5, 7 and 9) Class II b (HDAC 6 and 10) Class III (sirtuins) and Class IV (HDAC11) based on sequence homology, substrate preference and co-factor requirements. The involvement of each of these isoforms in disease pathology has been elucidated to some extent in recent times. The approval of suberoylanilide hydroxamic acid (SAHA) ${ }^{11}$, a well known inhibitor of HDACs by the US FDA for treating CTCL, (cutaneous $\mathrm{T}$ cell lymphoma $)^{12,13}$ has thrown open the doors for exploring the use of HDAC inhibitors in combination with existing drugs for several diseases, such as malaria and Kala-azar etc., ${ }^{14-16}$.

Class specific inhibitors are now becoming a reality for human HDAC isoforms. For example the HDAC Class I specific inhibitor MS-275 is in advanced clinical trials (clinical trial Nos. NCT00020579, NCT00866333) for several forms of cancer, and the HDAC class II specific inhibitor ACY-1215 is at an advanced clinical phase (clinical trial Nos. NCT01323751, NCT01583283) for myeloma.

HDAC inhibitors have been shown to synergize the actions of antifungal agents, due to their effect on preventing drug resistance in vitro ${ }^{17,18}$. Therefore, an alternative approach to address fungal drug resistance could be to harness the potential of modulating fungal gene expression by inhibition of fungal HDACs ${ }^{17,19}$.
Hos2, a class I HDAC enzyme plays an important role in gene activation in the yeast Saccharomyces cerevisiae by binding to open reading frames (ORFs) of active genes ${ }^{20}$. Hos $2 /$ Set 3 histone deacetylase complex (Set3C) plays a key role in the conversion of white phase to virulent opaque phase in $C$. albicans $^{21}$. Deletion of Hos2, the catalytic subunit of the Set 3 complex produced a phenotype resembling inhibition of the Set3C by Trichostatin-A (TSA) ${ }^{22}$. Serum-induced morphogenesis of some $C$. albicans strains was shown to be inhibited by TSA ${ }^{19}$. Thus inhibiting the morphogenetic ability of this opportunistic pathogen using HDAC inhibitors holds the promise of future antifungal agents. Recently a small molecule, MGCD 290 (Hos2 inhibitor) has entered clinical trials (clinical trial number NCT01497223)) for use in combination with azoles, such as fluconazole, for fungal infections ${ }^{18}$.

In light of the emerging utility of Hos2 inhibition as an anti-fungal strategy, we have cloned and characterized the C. albicans HOS2. In this report, we present details on optimizing the codons and cloning for heterologous gene expression in Sf9 insect cells. Purified Hos 2 was characterized by functional deacetylase activities on histone/tubulin preparations and inhibition studies with SAHA, TSA and MS-275. The Candida genome database reports Hos2 to be a putative NAD+ dependent histone deacetylase ${ }^{23}$, reminiscent of sirtuins. The Candida genome encodes for 3 sirtuins (HST1, HST2 and HST3). It has been shown that inhibition of HST3 by either gene repression or nicotinamide treatment reduces to a considerable extent the clinical severity of candidiasis ${ }^{24}$. In light of this reported observation, we checked for sirtuin like activity of purified Hos 2 preparations using resveratrol, which activates sirtuins ${ }^{25}$.

\section{Materials and methods}

\section{Isolation of $C$. albicans genomic DNA}

C. albicans ATCC 90028 was obtained from ATCC and grown in Sabouraud dextrose media. The protoplasts were prepared from an overnight culture of fully-grown mycelia using zymolyase (Cat. No. L5263, Sigma, St. Louis, MO, USA) as per the manufacturer's instructions. Protoplasts were lysed in a chaotrophic salt solution and genomic DNA was isolated according to manufacturer's instruction (Qiagen, Hilden, Germany). The final eluate was reprecipitated with ammonium acetate and isopropanol and DNA quantified by UV spectrophotometer (Spectramax Gemini XS, Molecular devices, CA. USA).

\section{Cloning and expression of HOS2 in an insect cell expression system}

Oligos were designed with codon changes made for $4^{\text {th }}$ and $271^{\text {st }}$ serine residues. Full length HOS 2 gene was amplified by using

Table 1. Oligonucleotide primer pairs for the PCR amplification of Hos2 gene by SOE PCR.

\begin{tabular}{|c|c|c|}
\hline $\begin{array}{l}\text { SI. } \\
\text { No. }\end{array}$ & $\begin{array}{l}\text { Primer } \\
\text { Name }\end{array}$ & Primer sequence \\
\hline 1 & PR1 & 5' AAAAGGATCCATGACGATATCCATAAGTGAAACAGATACG 3' \\
\hline 2 & PR2 & 5' ATTATTTAAATCCATTATGGAACCGTTAAT 3' \\
\hline 3 & PR3 & 5' ATTAACGGTTCCATAATGGATTTAAATAAT 3' \\
\hline 4 & PR4 & 5' CACCACTAGCGGCCGCTAAGTCATTAGTTCTCCTAGTTTGGTTTCA 3' \\
\hline
\end{tabular}


4 different primers (Table 1) using splicing by overlap extension (SOE PCR), so that codon usage could be maintained in any heterologous expression system. The full-length blunt end PCR product was cloned in to pJET1.2 cloning vector (CloneJET PCR Cloning Kit Thermo Scientific) and confirmed by restriction digestion using BamH1 and Not1. DNA sequencing using T7 promoter (forward, 5'-TAATAC GACTCACTATAGGG-3') and pJET1.2 (reverse, 5'-AAGAACATCGATTTTCCATGGCAG-'3) sequencing primer ascertained the sequence of the recombinant Hos2 gene.

Recombinant baculoviruses were generated using the Bac-to-Bac ${ }^{\circledR}$ baculovirus expression system according to the instructions of the manufacturer (Cat. No. 10359-016, Invitrogen, Carlsbad, USA). Sf9 insect cells (Cat. No. B825-01, Invitrogen, Carlsbad, USA) were cultured in complete TMN-FH medium (Cat. No. 554760, BD Bioscience, NJ, USA) served as host cells for virus generation and/or protein production. The HOS2 gene was cloned in frame with $\mathrm{N}$ terminal hexa-histidine tag into the transfer vector $\mathrm{pFastBac-HT} \mathrm{B}$ (Cat. No. 10584-027, Invitrogen, Carlsbad, USA) and transformed in to Escherichia coli DH10Bac cells (Cat. No. 10361-012, Invitrogen, Carlsbad, USA). Sf9 cells were transfected using cellfectin reagent (Cat. No. 10362-100, Invitrogen, Carlsbad, USA) with the recombinant bacmid, and the resulting viruses were tested for their ability to produce recombinant Hos 2 protein using western blot. Production cultures were performed T-150 cell culture flasks (Greiner bio-one $\mathrm{GmbH}$, Germany) at a density of $16 \times 10^{6}$ cells per flask. The cultures were inoculated with recombinant baculovirus stocks at multiplicities of infection of 10. At 4 days after infection, cells were harvested by centrifugation at $1200 \mathrm{~g}$ for $15 \mathrm{~min}$ at $4^{\circ} \mathrm{C}$ in a tabletop centrifuge (Model 5804R, Eppendorf AG, Hamburg, Germany). Cell pellets were stored at $-80^{\circ} \mathrm{C}$ until protein purification.

\section{Purification of recombinant Hos2 protein}

The infected Sf9 cell pellets were resuspended in in-house ice-cold lysis buffer $[10 \mathrm{mM}$ Tris $\mathrm{pH} 7.5,130 \mathrm{mM} \mathrm{NaCl}, 1 \%$ triton $\mathrm{X}-100$, $10 \mathrm{mM} \mathrm{NaF}, 10 \mathrm{mM}$ NaPi (sodium phosphate), and $10 \mathrm{mM} \mathrm{NaPPi}$ (sodium pyrophosphate)] with $1 \mathrm{X}$ EDTA free protease inhibitor cocktail (Cat. No. 539134, Calbiochem, Merck-Millipore, San Diego, CA). Insoluble material was removed by centrifugation (Model 5804R, Eppendorf AG, Hamburg, Germany) at $16000 \mathrm{~g}, 4^{\circ} \mathrm{C}$ for $15 \mathrm{~min}$. The cleared lysate was processed for nickel affinity chromatography. Briefly, the cell supernatant was loaded onto a 3-ml nickel-nitrilotriacetic acid-agarose resin (Ni-NTA agarose, Cat. No. 30210, Qiagen, Hilden, Germany) packed column pre-equilibrated with equilibration buffer ( $25 \mathrm{mM}$ Tris- $\mathrm{Cl} \mathrm{pH} 8.0,300 \mathrm{mM} \mathrm{NaCl})$. The column was washed with wash buffer $(25 \mathrm{mM}$ Tris-Cl $\mathrm{pH} 8.0$, $300 \mathrm{mM} \mathrm{NaCl}, 20 \mathrm{mM}$ imidazole). His-tagged Hos2 protein was eluted with buffer containing $300 \mathrm{mM}$ imidazole (Sigma, St. Louis, MO, USA). The Hos2 protein preparation was dialyzed into buffer (25 mM Tris, pH 8.0, $138 \mathrm{mM} \mathrm{NaCl}, 10 \%$ glycerol) and kept in 100 $\mu \mathrm{l}$ aliquots at $-70^{\circ} \mathrm{C}$. The concentration of Hos 2 protein in the final eluate was estimated by Bradford assay (Bio-Rad Laboratories, CA, USA).

Hos2 deacetylase enzymatic assay

HDAC inhibitors, namely SAHA, TSA or MS-275 were dissolved in DMSO as $10 \mathrm{mM}$ stock and subsequently diluted in $1 \mathrm{X}$ assay buffer (50 mM Tris Cl, pH 8.0, $137 \mathrm{mM} \mathrm{NaCl}, 2.7 \mathrm{mM} \mathrm{KCl,} 2.5 \mathrm{mM}$ $\mathrm{MgCl}_{2}, 1 \mathrm{mg} / \mathrm{ml} \mathrm{BSA}$ ). Enzymatic assay was carried out using the fluorogenic Class I HDAC substrate, Boc-Lys (Ac)-AMC (Cat. No. I1875, Bachem AG, Bubendorf, Switzerland). Briefly, $0.5 \mu \mathrm{g}$ of purified recombinant protein in a volume of $10 \mu \mathrm{l}$ of assay buffer was incubated with $50 \mu \mathrm{l}$ of appropriate concentration of HDAC inhibitors and $20 \mu \mathrm{M}$ of substrate at $37^{\circ} \mathrm{C}$ for $1 \mathrm{hr}$. Reactions were terminated by the addition of trichostatin A (TSA)/suberoylanilide hydroxamic acid (SAHA), trypsin $(1 \mathrm{mg} / \mathrm{mL})$ (Sigma, St. Louis, $\mathrm{MO}$, USA) and left at $37^{\circ} \mathrm{C}$ for $15 \mathrm{~min}$, before reading the plates in a fluorimeter (Spectramax Gemini XS, Molecular devices, CA. USA) at wavelengths $360 \mathrm{~nm}$ (ext) and $460 \mathrm{~nm}$ (emi).

\section{Production of polyclonal anti sera against Hos2 protein}

Female BALB/c mice were purchased from The Jackson Laboratory (Bar Harbor, ME) at 4 weeks of age and then housed at the animal facility, Orchid chemicals and Pharmaceuticals for 2 weeks in a specificpathogen free facility with a $12 \mathrm{~h}$ light cycle $(6 \mathrm{am}-6 \mathrm{pm})$ and a $12 \mathrm{~h}$ dark cycle ( $6 \mathrm{pm}-6 \mathrm{am})$. Groups of four mice were housed in sterilised polypropylene cages covered with stainless steel grid top, lined with autoclaved clean rice husk bedding. All animal experimentations were approved by the institutional animal ethics committee (Protocol No. 01/IAEC-05/PPK/2009). The native Hos2 protein (expressed in pET-32 bacterial vector system and purified using nickel affinity chromatography under denaturating conditions) was emulsified in complete Freund's adjuvant and injected subcutaneously into two female $\mathrm{BALB} / \mathrm{c}$ mice $(20 \mu \mathrm{g} /$ mice $)$. Booster doses of the deacetylase antigen ( $20 \mu \mathrm{g} /$ mice) were given on the $14^{\text {th }}$ and $21^{\text {st }}$ day in Freund's incomplete adjuvant. Mice were bled 7 days after the second booster dose and polyclonal anti sera was separated after clotting the blood ${ }^{26}$.

\section{Cell culture}

Jurkat, a human T lymphocyte cell line, and HeLa, a human cervical adenocarcinoma cell line was obtained from ATCC and were cultured in DMEM (Gibco, Life technologies) supplemented with $10 \%$ (v/v) fetal calf serum (FCS), 2 mM glutamine, 100 units $/ \mathrm{ml}$ penicillin and $100 \mu \mathrm{g} / \mathrm{ml}$ streptomycin (Gibco, Life technologies).

\section{Isolation of nuclear histones from mammalian cells}

Acetylated histones were isolated from HeLa cells treated with the HDAC inhibitor SAHA as per published protocol ${ }^{27}$. The histone pellet was then resuspended in ultra pure water, stored in $50 \mu \mathrm{l}$ aliquots at $-70^{\circ} \mathrm{C}$ and the protein concentration was determined using a BCA kit (Pierce).

\section{Isolation of histones from Candida sp.}

C. albicans ATCC 90028 mycelia ( 5 gm wet weight) were washed with water, centrifuged at $10,000 \mathrm{rpm}$ for 10 minutes at $4^{\circ} \mathrm{C}$ and the mycelial pellet was resuspended in $50 \mathrm{ml}$ of $0.1 \mathrm{mM}$ Tris- $\mathrm{HCl}$, pH 9.4, 10 mM DTT. The sample was incubated with shaking at $30^{\circ} \mathrm{C}$ for $15 \mathrm{~min}$ and pelleted. The pellet was washed with $50 \mathrm{ml}$ of sorbitol/HEPES buffer (1.2 M sorbitol, $20 \mathrm{mM}$ Hepes, pH 7.4) and left resuspended in the same buffer containing lyticase (1000 units) overnight at $30^{\circ} \mathrm{C}$ for spheroplasting ${ }^{28}$. The sample was pelleted and proceeded to histone isolation using acid extraction as described previously $^{29}$. Acetone was added at $3: 1(\mathrm{vol} / \mathrm{vol})$ to precipitate the histones, which were subsequently dissolved in $10 \mathrm{mM}$ Tris, $\mathrm{pH}-8.0$. 


\section{Deacetylation of nuclear histones}

Acetylated histones isolated from SAHA treated HeLa cells were used for the deacetylation assay with recombinant Hos2 enzyme. In brief, purified acetylated histones $(2 \mu \mathrm{g})$ were incubated with different amounts of recombinant Hos 2 enzyme. Histone deacetylation with $300 \mathrm{ng}$ of rhHDAC1 or rhHDAC6 (expressed in-house using Baculo-viral expression system) was used as a positive control. Deacetylation assays were carried out for $1 \mathrm{hr}$ at $37^{\circ} \mathrm{C}$ in reaction buffer (50 mM Tris Cl, pH 8.0, $137 \mathrm{mM} \mathrm{NaCl}, 2.7 \mathrm{mM} \mathrm{KCl}, 2.5 \mathrm{mM}$ $\left.\mathrm{MgCl}_{2}, 1 \mathrm{mg} / \mathrm{ml} \mathrm{BSA}\right)$. At the end of incubation, the reaction was stopped by the addition of $1 \mathrm{X}$ Lammeli sample buffer. The protein samples were resolved by SDS-PAGE and immunoblotted with antiacetylated H3 Histone (Ac-K-9) antibody to study the deacetylation of H3-histone by rHos2.

\section{Deacetylation of acetylated tubulin}

Whole cell extracts from TSA (Sigma, St. Louis, MO, USA) treated Jurkat cells were used for the $\alpha$-tubulin deacetylation assay with recombinant Hos 2 enzyme. In brief, whole cell extract $(10 \mu \mathrm{g})$ were incubated with 5 and $8 \mu \mathrm{g}$ of recombinant Hos 2 protein. Deacetylation assays were carried out for $3 \mathrm{hr}$ at $37^{\circ} \mathrm{C}$ in reaction buffer (50 mM Tris-Cl, pH 8.0, $137 \mathrm{mM} \mathrm{NaCl}, 2.7 \mathrm{mM} \mathrm{KCl}, 2.5 \mathrm{mM}$ $\mathrm{MgCl}_{2}$ ). At the end of incubation, the reaction was stopped by the addition of 1X Lammeli sample buffer. The protein samples were resolved by SDS-PAGE and immunoblotted with either anti-acetylated $\alpha$-tubulin or anti- $\alpha$-tubulin antibodies.

\section{Western blotting}

Recombinant Hos 2 protein or the acetylated/deacetylated nuclear histones from deacetylation assays were separated on 10-15\% SDS-polyacrylamide gels. The gels were stained with coomassie blue (Phast gel, Aersham) or electro-blotted onto nitrocellulose membrane (HyBond-C, Amersham), which was blocked with 5\% nonfat dry milk (Cat No. 70166, Fluka, Sigma-Aldrich) in $0.1 \%$ Tween- 20 in TBS for $1 \mathrm{hr}$, followed by overnight incubation at $4^{\circ} \mathrm{C}$ with either the polyclonal mouse serum (dilution 1:4000 of the sera), rabbit polyclonal anti-acetylated $\mathrm{H} 3$-Histone (dilution 1:4000, AcK-9 of H3-Histone, Cat. No. 06-599; Millipore), mouse monoclonal anti-acetylated tubulin (dilution 1:15000, Cat. No. T7451, Sigma) or mouse monoclonal anti-tubulin antibody (dilution 1:150000, Cat. No. T6199, Sigma). After incubation with the appropriate horseradish peroxidase conjugated secondary antibodies (Bovine anti-mouse IgG HRP conjugate-dilution 1:7500, Santa Cruz, SC2371, Goat anti-rabbit IgG-HRP Upstate (Millipore) 12-348, dilution 1:4000), supersignal west pico substrate (Thermo Scientific Pierce) was used for detection.

\section{In vitro Sirt1 activation assay}

HeLa nuclear extract $(2 \mu \mathrm{g})$ or recombinant Hos2 enzyme (300 ng) was incubated with NAD+ $(500 \mu \mathrm{M})$, Fluor de Lys ${ }^{\circledR}-$ Sirt1 (Enzo lifescience), varying concentrations of resveratrol (Cat. No. 0219605205, MP Biomedicals, Ohio, USA) (30, 100, 250 and $500 \mu \mathrm{M})$ in presence or absence of the pan-HDAC inhibitor trichostatin, at $37^{\circ} \mathrm{C}$ for $30 \mathrm{~min}$. The reaction was carried out following manufacturer's protocol (Enzo lifescience).

\section{Results}

HOS2 gene PCR

Codon usage in C. albicans is different from standard genetic code. The $4^{\text {th }}$ serine and the $271^{\text {st }}$ serine of HOS2 are translated as leucine in both mammalian and in insect cell expression systems. Hence, these codons were mutated using oligonucleotide primers to express serine in the recombinant Hos 2 protein. The PCR product was cloned in the pFastbac-HTB shuttle vector and subsequently into baculo viral DNA using the Bac-to-Bac expression system.

\section{Protein expression and purification}

The Hos2 enzyme was expressed in the baculoviral-insect cell expression system as a $\mathrm{NH}_{2}$-terminal hexa histidine tagged fusion protein, which is detected on Western blot as a $\sim 52 \mathrm{kDa}$ protein using our own polyclonal anti-Hos 2 anti-sera raised against Hos 2 protein in mice. SDS-PAGE analysis of purified protein revealed a major band at $\sim 52 \mathrm{kDa}$ (Figure $1 \mathrm{~A}$ ).

A

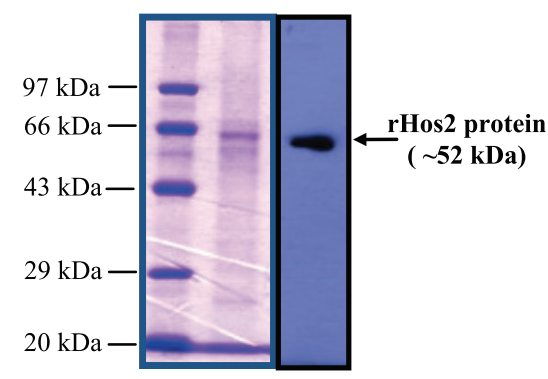

B

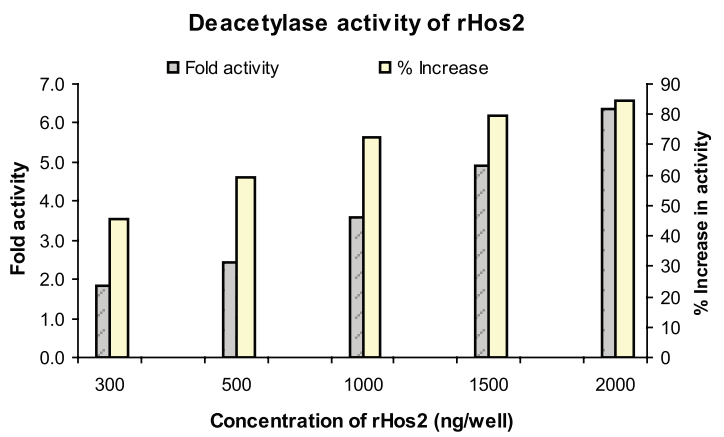

Figure 1. Expression of his-tagged Hos2 in insect cells and its characterization. (A) Sf9 cells were infected with $10 \mathrm{MOI}$ of recombinant Hos2 baculovirus for 72 hours and the soluble fraction was collected. Two $\mu \mathrm{g}$ of protein was separated on a $10 \%$ SDSPAGE. Lane 2 is coomassie stained SDS-PAGE and Lane 3 is Hos2 protein recognized by polyclonal anti sera from mice. Molecular weight markers are labeled at the left side (Lane 1) of the blot. (B) Concentration dependent increase in deacetylase activity following incubation of baculo expressed Hos2 with Boc-lys (ac)-AMC fluorogenic peptide substrate in $1 \mathrm{hr}$ assay at $37^{\circ} \mathrm{C}$. 
Tubulin deacetylation and rHos2 protein blots

2 Data Files

http://dx.doi.org/10.6084/m9.figshare.841666

In vitro deacetylation assay using synthetic peptide substrate

Recombinant Hos 2 enzyme was assayed for deacetylase activity using the synthetic deacetylase substrate, Boc-Lys (ac)-AMC. The total activity with Boc-Lys (ac) AMC showed the enzyme to be active in deacetylating the lysine residue and the activity increased with an increase in Hos2 concentration (Figure 1B).

The inhibition of deacetylation activity of recombinant Hos 2 was studied using classical HDAC inhibitors namely SAHA, TSA and MS-275. TSA was very potent in inhibiting Hos2 with an $\mathrm{IC}_{50}$ of $2.8 \mathrm{nM}$, SAHA inhibited Hos2 with an $\mathrm{IC}_{50}$ of $65 \mathrm{nM}$ (Figure 2, Table 2). However, MS-275 showed $>50 \%$ inhibition of Hos2 activity only at $10 \mu \mathrm{M}$ (Table 3).

\section{In vitro deacetylation assay using natural substrates}

The ability of purified Hos 2 protein to deacetylate acetylated histones was examined in vitro using acetylated nuclear histone preparation made from SAHA treated HeLa cells. The nuclear histones from HeLa cells were isolated using a modified protocol of Shechter et al. ${ }^{27}$ and established the deacetylation assay using rhHDAC1/rhHDAC6 as controls along with $\mathrm{rHos} 2$. In these assays it was found that 0.3 $\mu \mathrm{g}$ of rhHDAC1 was able to deacetylate the nuclear acetylated histones as detected by an anti-H3-K9 histone antibody. Recombinant hHDAC1 was more potent in deacetylating lysine residues in $\mathrm{H} 3$ histones than rhHDAC6. However, no significant deacetylation of H3-Histone was seen with $0.3 \mu$ g of Hos2 (Figure 3A). Similar results were obtained with acetylated histones from Candida in the in vitro histone deacetylation assay with purified Hos2 protein (up to $3 \mu \mathrm{g}$, Figure 3B). In contrast, when recombinant Hos 2 was incubated with mammalian acetylated $\alpha$-tubulin, a significant reduction in acetylation of $\alpha$-tubulin (K40) could be observed (Figure 4).

Table 2. IC50 values of standard HDAC inhibitors.

\begin{tabular}{lll} 
SI. No. & Pan HDAC inhibitor & IC $_{50} \pm$ SE $(\mathbf{n M})$ \\
\hline 1 & SAHA & $65.4 \pm 2.4$ \\
2 & TSA & $2.8 \pm 0.9$
\end{tabular}

Table 3. Hos2 enzyme inhibition values of Class I HDAC inhibitor.

\begin{tabular}{|llll} 
SI. No. & Class I HDAC inhibitor & \multicolumn{2}{c}{$\%$ inhibition \pm SE } \\
\cline { 2 - 3 } & $\mathbf{1 0} \boldsymbol{\mu M}$ & $\mathbf{1} \boldsymbol{\mu M}$ \\
\hline 1 & MS275 & $56.3 \pm 0.9$ & $46.3 \pm 1.4$ \\
\hline
\end{tabular}

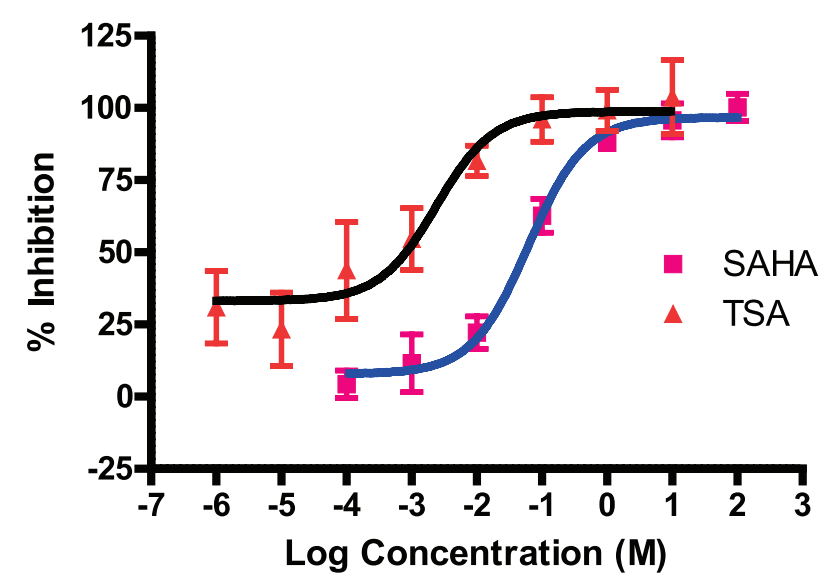

Figure 2. Dose-dependent inhibition of Hos2 deacetylase activity by SAHA (squares) and TSA (triangles). Recombinant Hos2 enzyme was incubated with different concentrations of panHDAC inhibitors (SAHA or TSA) and the enzyme activity assay was performed.

Deacetylase activities of rHos2 and dose response curves of rHos2 inhibition by standard HDAC inhibitors

4 Data Files

http://dx.doi.org/10.6084/m9.figshare.841655

In vitro Sirt1 deacetylation assay using fluor-de-lys substrate

Since Hos 2 is a putative NAD+ dependent deacetylase, a feature of sirtuin class of deacetylases, it was of interest to check if the Hos2 protein displayed any sirtuin like activity. The sirtuin-like activity in response to the sirtuin activator resveratrol was studied using fluor-de-lys, a synthetic Sirt1 substrate. HeLa nuclear extract was used as a positive control for sirtuin activity. In the presence of TSA where the HDAC activities are inhibited no appreciable NAD+ dependent deacetylase-like activity was seen, following incubation of Hos2 with different concentrations of resveratrol (Figure 5).

Sirtuin assay of purified Hos2 preparations using resveratrol

3 Data Files

http://dx.doi.org/10.6084/m9.figshare.841658

\section{Discussion}

Hos2 is a histone deacetylase and interacts with several proteins both in the cytoplasmic milieu as well in the nucleus ${ }^{30}$. Hos 2 along with Set3 (SET domain-containing protein 3) an associated protein, plays an important role in controlling gene expression by associating with transcriptionally active regions of the chromatin ${ }^{31}$. 
A

\section{Acetyl-H3-Histone $\sim 17 \mathrm{kDa}$}

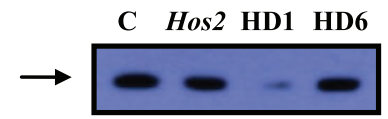

B

\section{Acetyl-H3 Histone $\sim 17 \mathrm{kDa}$}



Figure 3. Deacetylation assays of deacetylases with nuclear histones. A. Histone H3 acetylation determined by Western blot of extracted acetylated histones $(2 \mu \mathrm{g})$ Control (Lane 1), incubated with $300 \mathrm{ng}$ of recombinant Hos2 protein (Lane 2), recombinant human HDAC1 (HD1 Lane 3) and recombinant human HDAC6 (HD6 Lane 4) for 1 hour at $37^{\circ} \mathrm{C}$ in HDAC assay buffer. B. Histone H3 acetylation determined by Western blot of extracted acetylated histones $(2 \mu \mathrm{g})$ isolated from $C$. albicans, incubated with different concentrations of recombinant Hos2 protein for 1 hour at $37^{\circ} \mathrm{C}$ in HDAC assay buffer.

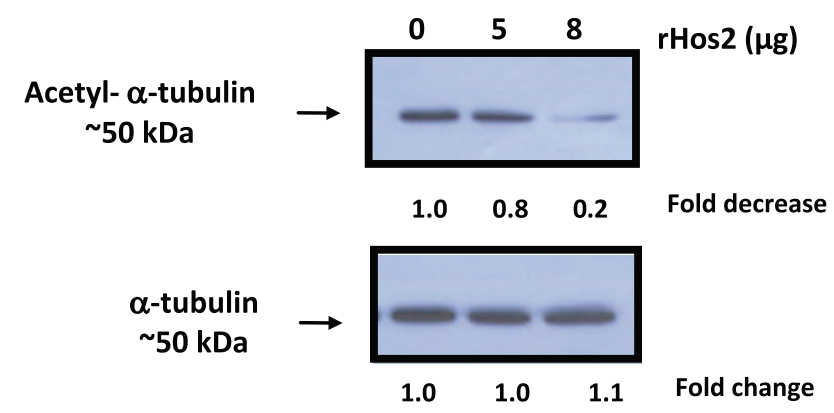

Figure 4. Deacetylation assays or rHos2 with H3-histones and $\alpha$ tubulin. $\alpha$-tubulin acetylation determined by Western blot of SAHAtreated whole cell extracts containing acetylated $\alpha$-tubulin $(10 \mu \mathrm{g})$ incubated with 0,5 or $8 \mu \mathrm{g}$ of recombinant Hos 2 for $3 \mathrm{hrs}$ at $37^{\circ} \mathrm{C}$ in HDAC assay buffer.

HDAC inhibitors by virtue of their ability to prevent antifungal resistance in vitro have been proposed as antifungal adjuvants. It has been surmised that inhibiting Hda1 for example might enhance the antifungal effect of HDAC inhibitors by limiting hyphal development, while inhibiting Hos 2 might contribute to limiting yeast development ${ }^{32}$. Hos 2 has an essential function in morphogenesis especially during conditions of nitrogen starvation ${ }^{33}$. The critical role of HDAC's in $C$. albicans pathogenesis and survival to antifungal treatment underscores the necessity to study HDAC function in this organism.

The increasing clinical incidences of azole resistant fungal infections in critical care patients, makes a good reason to find additional drug targets to control such diseases. There is at least one small molecule (MGCD 290) that inhibits Hos2 histone deacetylase that has progressed to clinical trials. MGCD 290 in combination with azoles was shown to be active against azole resistant yeasts and moulds ${ }^{18}$.

In order to better understand the role played by the Candida Hos 2 enzyme we attempted to clone, express and characterize the protein in detail. This study describes the cloning, expression, purification and characterization of the Hos2 deacetylase enzyme from C. albicans.

We cloned and expressed the HOS2 gene in baculoviral expression system as a $6 \mathrm{x}$ his-tagged protein, which exhibits classical deacetylase activity with the synthetic Boc-Lys (ac)-AMC peptide substrate. In our study, the yield of the Hos 2 protein was generally low and probably could be attributed to difference in codon usage between Candida and Sf9 insect cells. This in vitro enzymatic assay, amenable to high throughput, could be used for screening potent fungal Hos 2 inhibitors that could be a potential anti-fungal adjuvant.

Our studies with the recombinant Hos 2 protein showed that it is susceptible to inhibition by standard HDAC inhibitors such as SAHA and TSA. We characterized the inhibition profile of purified proteins with SAHA and TSA and showed that TSA is a more potent inhibitor of Hos 2 with an $\mathrm{IC}_{50}$ of $2.8 \pm 0.9 \mathrm{nM}$ compared to SAHA $\left(\mathrm{IC}_{50} 65.4 \pm 2.4 \mathrm{nM}\right)$. Our studies with the class I HDAC inhibitor MS-275 showed that this inhibitor did not inhibit Hos2 deacetylase as effectively as the pan HDAC inhibitors SAHA or TSA, suggesting that Candida Hos2 is more similar to class II deacetylases.

The recombinant Hos 2 failed to deacetylate either mammalian or fungal nuclear histones, suggesting that the histones are not the

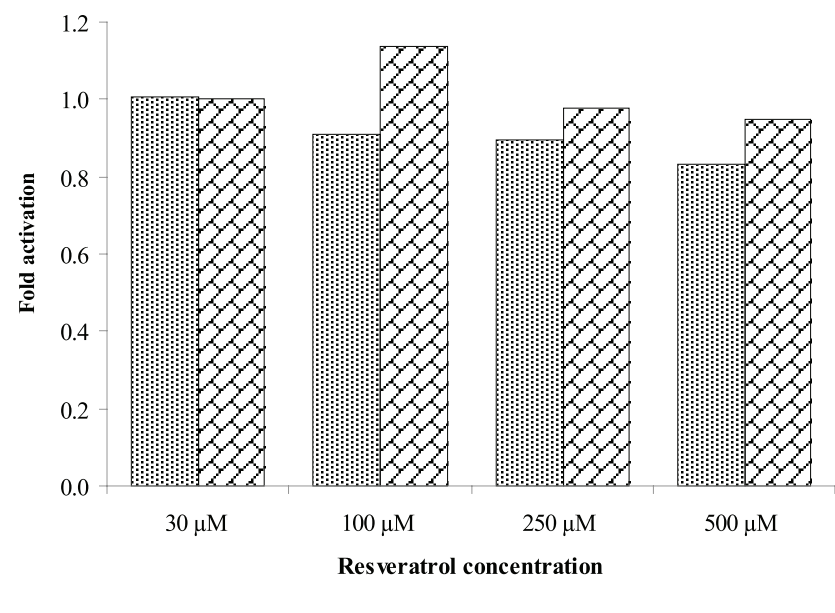

Total activity without trichostatin Total activity with trichostatin

Figure 5. SIRTI activation following incubation of Resveratrol with rHos2. Fold activation of the Sirt1 like activity following incubation of recombinant Hos2 enzyme with different concentration of resveratrol in presence and absence of HDAC inhibitor trichostatin. 
preferred substrates for the Hos2 enzyme. Experiments with total lysates from Jurkat cells containing acetylated $\alpha$-tubulin showed a dose dependent deacetylation albeit at higher concentration of Hos2 (> $5 \mu \mathrm{g})$. Hos 2 in essence resembles the class II mammalian HDACs, specifically HDAC6 in its preference for tubulin deacetylation. The physiological relevance of tubulin deacetylation by Hos2 warrants further study.

The Candida genome database ${ }^{23}$ predicts Hos 2 protein to be a NAD+ dependent deacetylase. Sirtuins which are classified as Class III deacetylases are NAD+ dependent enzymes activated by polyphenols such as resveratrol. Sirtuins have been proposed to regulate cellular metabolism, ageing and other related processes, specifically cellular stress response to caloric restriction, mediating life span extension. The role of resveratrol as a sirtuin activator has been resolved recently and it is now known that in addition to activating Sirt1, it also activates Sirt5, while inhibiting Sirt $3^{25}$. Thus inhibiting any sirtuin like activity with small molecule inhibitors could be another way of enhancing the activity of currently used anti-fungals. We evaluated the possibility of Hos 2 being a sirtuin like enzyme with a known Sirt1 activator resveratrol. We did not observe any significant activation of NAD+ dependent deacetylase activity with the fluor-de-lys substrate.

In conclusion this study establishes a functional assay for purified Hos 2 protein. This in vitro enzymatic assay can be used to screen small molecule inhibitors of Hos2, which can synergise current anti-fungals in the clinic.

\section{Author contributions}

GK, MPS and SN conceived the study. GK, NDM and RG designed the experiments. GK, NDM and RG carried out the research. GK and NDM prepared the first draft of the manuscript. All authors were involved in the revision of the draft manuscript and have agreed to the final content.

\section{Competing interests}

No competing interests were disclosed.

\section{Grant information}

This was an exploratory in-house project funded solely by Orchid Chemicals and Pharmaceuticals Limited.

The funders had no role in study design, data collection and analysis, decision to publish, or preparation of the manuscript.

\section{Acknowledgements}

The authors thank Dr. B. Gopalan, Chief Scientific Officer (CSO) for the encouragement and support and the Management of Orchid Chemicals and Pharmaceuticals Limited (www.orchidpharma.com), Chennai, India, for encouraging publication of this research.
1. Odds FC: Candida and candidosis: a review and bibliography: Bailliere Tindall; 1988.

Reference Source

2. Pfaller MA, Diekema DJ, Jones RN, et al:: International surveillance of bloodstream infections due to Candida species: frequency of occurrence and in vitro susceptibilities to fluconazole, ravuconazole, and voriconazole of isolates collected from 1997 through 1999 in the SENTRY antimicrobial surveillance program. J Clin Microbiol. 2001; 39(9): 3254-3259. PubMed Abstract | Publisher Full Text | Free Full Text

3. Fera MT, La Camera E, De Sarro A: New triazoles and echinocandins: mode of action, in vitro activity and mechanisms of resistance. Expert Rev Anti Infect Ther. 2009; 7(8): 981-998. PubMed Abstract | Publisher Full Text

4. Sanglard D, Ischer F, Koymans L, et al:: Amino acid substitutions in the cytochrome P-450 lanosterol 14alpha-demethylase (CYP51A1) from azoleresistant Candida albicans clinical isolates contribute to resistance to azole antifungal agents. Antimicrob Agents Chemother. 1998; 42(2): 241-253. PubMed Abstract | Free Full Text

5. White TC: The presence of an R467K amino acid substitution and loss of allelic variation correlate with an azole-resistant lanosterol 14alpha demethylase in Candida albicans. Antimicrob Agents Chemother. 1997; 41(7): 1488-1494. PubMed Abstract | Free Full Text

6. Song JL, Harry JB, Eastman RT, et al.: The Candida albicans lanosterol 14-alpha-demethylase (ERG11) gene promoter is maximally induced after prolonged growth with antifungal drugs. Antimicrob Agents Chemother. 2004: 48(4): 1136-1144.

PubMed Abstract | Publisher Full Text | Free Full Text

7. Sanglard D, Kuchler K, Ischer F, et al.: Mechanisms of resistance to azole antifungal agents in Candida albicans isolates from AIDS patients involve specific multidrug transporters. Antimicrob Agents Chemother. 1995; 39(11): 2378-2386

PubMed Abstract | Publisher Full Text | Free Full Text

8. Albertson GD, Niimi M, Cannon RD, et al:: Multiple efflux mechanisms are involved in Candida albicans fluconazole resistance. Antimicrob Agents Chemother. 1996; 40(12): 2835-2841.

PubMed Abstract | Free Full Text
9. Marr KA, Lyons CN, Rustad TR, et al.: Rapid, transient fluconazole resistance in Candida albicans is associated with increased mRNA levels of CDR. Antimicrob Agents Chemother. 1998; 42(10): 2584-2589. PubMed Abstract | Free Full Text

10. Clayton AL, Hazzalin CA, Mahadevan LC: Enhanced histone acetylation and transcription: a dynamic perspective. Mol Cell. 2006; 23(3): 289-296. PubMed Abstract | Publisher Full Text

11. Marks PA: Discovery and development of SAHA as an anticancer agent. Oncogene. 2007; 26(9): 1351-1356. PubMed Abstract | Publisher Full Text

12. Campas-Moya C: Romidepsin for the treatment of cutaneous T-cell lymphoma Drugs Today (Barc.). 2009; 45(11): 787-795. PubMed Abstract | Publisher Full Text

13. Duvic $\mathrm{M}, \mathrm{Vu} \mathrm{J}$ : Update on the treatment of cutaneous T-cell lymphoma (CTCL): Focus on vorinostat. Biologics. 2007; 1(4): 377-392. PubMed Abstract | Publisher Full Text | Free Full Text

14. Dokmanovic M, Clarke C, Marks PA: Histone deacetylase inhibitors: overview and perspectives. Mol Cancer Res. 2007; 5(10): 981-989. PubMed Abstract | Publisher Full Text

15. Mai A: The therapeutic uses of chromatin-modifying agents. Expert Opin Ther Targets. 2007; 11(6): 835-851. PubMed Abstract | Publisher Full Text

16. Riester D, Hildmann C, Schwienhorst A: Histone deacetylase inhibitors--turning epigenic mechanisms of gene regulation into tools of therapeutic intervention in malignant and other diseases. Appl Microbiol Biotechnol. 2007; 75(3): 499-514. PubMed Abstract | Publisher Full Text

17. Smith WL, Edlind TD: Histone deacetylase inhibitors enhance Candida albicans sensitivity to azoles and related antifungals: correlation with reduction in CDR and ERG upregulation. Antimicrob Agents Chemother. 2002; 46(11): 3532-3539. PubMed Abstract | Publisher Full Text | Free Full Text

18. Pfaller MA, Messer SA, Georgopapadakou N, et al:: Activity of MGCD290, a Hos2 histone deacetylase inhibitor, in combination with azole antifungals against opportunistic fungal pathogens. J Clin Microbiol. 2009; 47(12): 3797-3804. PubMed Abstract | Publisher Full Text | Free Full Text 
19. Simonetti G, Passariello C, Rotili D, et al.: Histone deacetylase inhibitors may reduce pathogenicity and virulence in Candida albicans. FEMS Yeast Res. 2007; 7(8): 1371-1380

PubMed Abstract | Publisher Full Text

20. Wang A, Kurdistani SK, Grunstein M: Requirement of Hos2 histone deacetylase for gene activity in yeast. Science. 2002; 298(5597): 1412-1414. PubMed Abstract | Publisher Full Text

21. Hnisz D, Schwarzmuller T, Kuchler K: Transcriptional loops meet chromatin: a dual-layer network controls white-opaque switching in Candida albicans. Mol Microbiol. 2009; 74(1): 1-15.

PubMed Abstract | Publisher Full Text | Free Full Text

22. Hnisz D, Majer O, Frohner IE, et al.: The Set3/Hos2 histone deacetylase complex attenuates CAMP/PKA signaling to regulate morphogenesis and virulence of Candida albicans. PLOS Pathog. 2010; 6(5): e1000889. PubMed Abstract | Publisher Full Text | Free Full Text

23. Arnaud MB ID, Skrzypek MS, Binkley J, et al.: Candida Genome Database. Reference Source

24. Wurtele H, Tsao S, Lepine G, et al:: Modulation of histone $\mathbf{H 3}$ lysine $\mathbf{5 6}$ acetylation as an antifungal therapeutic strategy. Nat Med. 2010; 16(7): 774-780. PubMed Abstract | Publisher Full Text

25. Gertz M, Nguyen GT, Fischer F, et al:: A molecular mechanism for direct sirtuin activation by resveratrol. PLOS One. 2012; 7(11): e49761. PubMed Abstract | Publisher Full Text | Free Full Text

26. Fuller SA, Takahashi M, Hurrell JG: Immunization of Mice. Curr Protoc Mol Biol.
John Wiley \& Sons, Inc.; 2001

PubMed Abstract | Publisher Full Text

27. Shechter D, Dormann $\mathrm{HL}$, Allis $\mathrm{CD}$, et al.: Extraction, purification and analysis of histones. Nat Protoc. 2007; 2(6): 1445-1457.

PubMed Abstract | Publisher Full Text

28. Yeast Nuclei Isolation

Reference Source

29. Knapp AR, Ren C, Su X, et al:: Quantitative profiling of histone post-translational modifications by stable isotope labeling. Methods. 2007; 41(3): 312-319. PubMed Abstract | Publisher Full Text | Free Full Text

30. Wiren M, Silverstein RA, Sinha I, et al:: Genomewide analysis of nucleosome density histone acetylation and HDAC function in fission yeast. EMBO J. 2005; 24(16): 2906-2918.

PubMed Abstract | Publisher Full Text | Free Full Text

31. Hnisz D, Bardet AF, Nobile CJ, et al:: A histone deacetylase adjusts transcription kinetics at coding sequences during Candida albicans morphogenesis. PLoS Genet. 2012; 8(12): e1003118. PubMed Abstract | Publisher Full Text | Free Full Text

32. Zacchi LF, Schulz WL, Davis DA: HOS2 and HDA1 encode histone deacetylases with opposing roles in Candida albicans morphogenesis. PLoS One. 2010; 5(8): e12171. PubMed Abstract | Publisher Full Text | Free Full Text

33. Robyr D, Suka $Y$, Xenarios I, et al:: Microarray deacetylation maps determine genome-wide functions for yeast histone deacetylases. Cell. 2002; 109(4): 437-446. PubMed Abstract | Publisher Full Text 


\section{Open Peer Review}

\section{Current Peer Review Status: ? ?}

\section{Version 1}

Reviewer Report 16 April 2014

https://doi.org/10.5256/f1000research.2168.r4017

(C) 2014 Soll D. This is an open access peer review report distributed under the terms of the Creative Commons Attribution License, which permits unrestricted use, distribution, and reproduction in any medium, provided the original work is properly cited.

\section{David Soll \\ Department of Biology, University of Iowa, Iowa City, IA, USA}

This manuscript describes an in vitro assay strategy for testing the effects of antifungal compounds on the activity of Hos 2 deacetylase large scale screens. The goal is to find compounds that could be used as facilitators in combinatorial drug treatments for azole resistant Candida albicans infections. Although in vitro assays are sometimes useful for developing in vivo strategies, they are not ideal for screening and identifying optimal drugs.

As shown in this study by the authors, the recombinant Hos2 they generated exhibits paradoxically tubulin-specific deacetylase activity and not Hos2 specific activity. This finding seems to undermine their intent, because anti-tubulin deacetylase activity or anti-human HDAC6 activity demonstrated in vitro could be an artifact of the recombinant protein. In addition, anti-tubulin and anti-HDAC6 activity might result in adverse side effects on human host functions and thus affect the specificity of the primary drug.

It is surprising that the recombinant Hos2 did not show any activity in acetylating either the human or Candida histone $\mathrm{H} 3$ in vitro, despite the fact that several earlier studies in C. albicans has demonstrated that Hos 2 is involved in morphogenetic programs by affecting chromatin function. In addition, an isolated study has demonstrated the efficacy of a Hos2-specfic inhibitor on azoleresistant strains of $C$. albicans (Pfaller et al., 2009), which is quoted by the authors. The authors do state in the introduction that Hos2 is not a typical deacetylase and has been described by the Candida Genome Database as a member of NAD-dependent sirtuins. The authors' data show that their recombinant version lacks this activity, but does exhibit inhibition by classical inhibitors of histone deacetylases.

In addition to this major problem there are a few other aspects of the paper that need to be addressed:

Firstly, Figure 1 and Figure 5 do not have error bars to indicate reproducibility of the data. Also, a statistical analysis of data sets would be useful to indicate the significance of the results. 
Secondly, the units in Figure 2 and Table 2 need to be consistent with the units described in the text.

Thirdly, since Figure 4 shows the effect of recombinant Hos 2 on only tubulin, the title needs to be changed to indicate that the assay was not done with purified histones.

Finally, it is not clear what "fold activity" (in Figure 1B) and "fold activation" (Figure 5) refer to.

Competing Interests: No competing interests were disclosed.

I confirm that I have read this submission and believe that I have an appropriate level of expertise to confirm that it is of an acceptable scientific standard, however I have significant reservations, as outlined above.

Author Response 13 May 2014

Karthikeyan Ganesan, Orchid Chemicals and Pharmaceuticals Limited, Chennai, India

As a pharmaceutical organization, involved in drug discovery, our initial compound libraries are screened for in vitro activity/inhibition assays. These in vitro assays act as important filters removing in-active compounds to progress only the most potent ones to in vivo screening.

Deacetylase assays using recombinant Hos2 enzyme and synthetic substrate Boc (Lys) AMC showed that the enzyme is active in standard fluorogenic assays. Absence of deacetylase activity with histone preparations (Human/Candida) in the in vitro histone deacetylation assays was a surprise but the fact that Class I HDAC inhibitor like MS-275 did not inhibit rHos2 in standard fluorogenic assays, led us to explore alternate substrate, namely tubulins.

We do agree with the reviewer that anti-tubulin deacetylase activity could be an artifact of recombinant protein, but we strongly feel that it is a remote possibility.

Any small molecule that shows anti-tubulin or anti-HDAC6 activity would be picked up in the in vitro screen and would be prevented from moving further up the discovery path. (Which can be re-purposed for different therapeutic )

We are indeed aware of the previous studies showing the effect of Set3/Hos 2 complex and the opposing roles of Hda1 and Hos2 in Candida morphogenesis as well as the role of Hos2 in S. cerevisiae. In these studies Histone $\mathrm{H} 4$ acetylation levels vary dramatically, especially H4-K16, however the Histone H3 levels more or less remain constant, (supplementary materials from Wang et al., 2002) and that's probably the reason why we don't see any dramatic deacetylation when probed with Histone H3-K9. The study by Pfaller et al. did have in vivo data, but did not have any in vitro data.

Error bars and statistical analysis have been incorporated for Figs. 1 and 5. Units for Fig. 2 and Table 2 corrected. 
Label has been changed for Fig. 4

Fold activity and Fold activation is with respect to Blank and has been reflected in the figures.

Competing Interests: No competing interests were disclosed.

Reviewer Report 19 March 2014

https://doi.org/10.5256/f1000research.2168.r4016

(c) 2014 MacCallum D. This is an open access peer review report distributed under the terms of the Creative Commons Attribution License, which permits unrestricted use, distribution, and reproduction in any medium, provided the original work is properly cited.

\section{Donna MacCallum}

Aberdeen Fungal Group, University of Aberdeen, Aberdeen, UK

This is an interesting study designed to examine the biological activities of Candida albicans Hos2 enzyme, a putative histone deacetylase. The authors express a recombinant version of the protein, which has a His tag added to the N-terminus, and use this to explore potential substrates for the enzyme.

There are a number of major issues with the data as presented, which need to be addressed: It is difficult to make any conclusions from the quantitative data presented in the figures as there are no error bars and the number of replicates is not stated. In addition, it is unclear what the data in Figures $1 \mathrm{~B}$ and 5 has been expressed relative to (i.e. fold change relative to...?) Statistical analyses should also be carried out to determine whether any differences are statistically significant ones.

The authors should also revisit the data presented in Figure 2 and Table 2. The data does not correlate, as the authors suggest that the $\mathrm{IC}_{50}$ values are in micromolar amounts, yet the data in the figure would suggest millimolar levels - units should be checked.

The title for Figure 4 should be modified, since this figure contains only data for betatubulin.

In the main text the authors need to be much clearer regarding the rationale for looking at tubulin as a substrate. The authors may also wish to consider the possibility that the substrate specificity and/or activity may have been affected by the N-terminal tag and how this could be investigated.

The discussion section should be revisited to remove the reiteration of the introduction and results. Instead, use this part of the paper to discuss the findings in relation to other published work.

Minor points:

Candida albicans is capable of causing superficial (oral and vaginal thrush) infections in 
immune normal hosts (abstract and introduction).

Gene names, e.g. CDR1 and ERG11, should be in italics.

For the enzymatic assay it would be good to state the volume of the assay so that final concentrations can be worked out.

Figure and table legends should include the number of replicates carried out to generate the data.

Competing Interests: No competing interests were disclosed.

I confirm that I have read this submission and believe that I have an appropriate level of expertise to confirm that it is of an acceptable scientific standard, however I have significant reservations, as outlined above.

Author Response 13 May 2014

Karthikeyan Ganesan, Orchid Chemicals and Pharmaceuticals Limited, Chennai, India

Error bars have been incorporated and where possible, statistical analysis done and reported.

Error in reporting $\mathrm{IC}_{50}$ value in Table 2 and Fig. 2 is corrected.

Title for Fig. 4 changed to reflect tubulin deacetylation.

The rationale for choosing tubulin as a substrate has been explained. We agree with the reviewer that $\mathrm{N}$-terminal tag could perhaps play a role, although we consider that as a remote possibility.

Minor points suggested by reviewer has also been addressed.

Competing Interests: No competing interest 
The benefits of publishing with F1000Research:

- Your article is published within days, with no editorial bias

- You can publish traditional articles, null/negative results, case reports, data notes and more

- The peer review process is transparent and collaborative

- Your article is indexed in PubMed after passing peer review

- Dedicated customer support at every stage

For pre-submission enquiries, contact research@f1000.com 